\title{
GAMBARAN TINGKAT PENGETAHUAN LANSIA TENTANG SENAM OTAK DI WILAYAH RW 06 KELURAHAN PAMOYANAN KOTA BANDUNG
}

\author{
${ }^{1}$ Susy Puspasari, ${ }^{2}$ Herni Martiani \\ ${ }^{1,2}$ STIKep PPNI Jawa Barat, Bandung, Jawa Barat - Indonesia \\ Email : eisya73@gmail.com
}

\begin{abstract}
Abstrak
Otak manusia seperti hologram, terdiri atas tiga dimensi dengan bagian-bagian yang saling berhubungan sebagai satu kesatuan. Latihan otak dapat membuat otak bekerja aktif. Jika lansia tidak mengetahui senam otak, maka lansia akan mengalami daya ingat yang kurang baik. Senam otak adalah rangkaian gerakan sederhana yang dapat menyeimbangkan setiap bagian otak atau latihan berbasis gerakan tubuh sederhana yang dapat dilakukan di mana saja dan kapan saja. Penelitian dilakukan bertujuan untuk megetahui gambaran tingkat pengetahuan lanjut usia tentang senam otak di wilayah RW 06 Kelurahan Pamoyanan Kota Bandung. Desain penelitian ini adalah penelitian deskriptif. Populasi dalam penelitian ini adalah lansia yang berusia 45-60 tahun sebanyak 345 orang, sedangkan jumlah sampel penelitian sebanyak 72 responden dengan menggunakan teknik purposive sampling. Kuesioner dikembangkan dengan mengacu pada tinjauan pustaka yang terdiri atas data pengetahuan tentang senam otak sebanyak 28 pernyataan. Berdasarkan hasil penelitian pengetahuan lanjut usia tentang senam otak di wilayah RW 06 Kelurahan Pamoyanan Kota Bandung tahun 2016 didapatkan bahwa 76,4\% memiliki pengetahuan baik tentang senam otak. Lansia yang berusia 45-60 tahun memiliki pengetahuan baik tentang senam otak. Diharapkan kepada petugas kesehatan di Puskesmas Pasirkaliki agar melakukan kegiatan senam otak.
\end{abstract}

Kata kunci : Lansia, Pengetahuan, Senam Otak

\begin{abstract}
The human brain is like a hologram, consisting of three-dimensional parts that are interconnected as a single unit. Brain gym can make the brain work actively. If the elderly do not know the brain exercise, the elderly will experience poor memory. Brain gym is a serial of simple gestures which known able to balance part of brain, or a simple body motion-based exercise that possibly to be done whenever, wherever. This research aims to portray characteristic of knowledge regarding brain gym among elderly in $R W$ 06, Pamoyanan District, City of Bandung.This study used a descriptive approach. Population in this research are elderly among 45-60 years old as much as 345 people, while research samples were as much as 72 respondents, in which sampling were done by purposive sampling technic. Questionnaire was developed by referring literature review consisted by statement regarding knowledge about brain gym as much as 28 questions. Results concluded that knowledge regarding brain gym in $R W$ 06, Pamoyanan District, City of Bandung, 76.4\% of respondent had adequate knowledge good brain gym. Elderly aged 45-60 years have a good knowledge about the brain gym. Expected to health workers in health centers in order to perform activities Pasirkaliki brain gym.
\end{abstract}

Keywords: Elderly, Brain Gymnastic, Knowledge

\section{PENDAHULUAN}

Jumlah lanjut usia terus meningkat. Menurut proyeksi WHO pada tahun 1995, bahwa pada tahun 2050 jika dibandingkan dengan tahun 1990, pertumbuhan penduduk lanjut usia Indonesia mengalami pertumbuhan terbesar di Asia, yaitu sebesar 414\%,
Thailand $337 \%$, India $242 \%$ dan China $220 \%$. Jumlah lanjut usia Indonesia menurut BPS bahwa tahun 2004 sebesar 16.522.311, tahun 2006 sebesar 17.478.282 dan pada tahun 2008 sebesar $19.502 .355(8.55 \%$ dari total penduduk sebesar 228.018.900), sedangkan pada tahun 2020 diperkirakan 
jumlah lansia sekitar 24 juta jiwa. (Komnas Lansia, 2011).

Menurut estimasi kependudukan tahun 2011 penduduk terbesar Indonesia 43.867.447 jiwa. Kota Bandung peringkat lima terbesar yang mempunyai penduduk sebanyak 2.440 .136 jiwa. Secara estimasi, populasi penduduk lansia (usia di atas 60 tahun) di Kota Bandung tahun 2014 sebanyak 187.173 jiwa (Dinkes Kota Bandung, 2014).

Seiring dengan meningkatnya usia harapan hidup, jumlah penduduk lansia (lanjut usia) atau di atas enam puluh tahun, diperkirakan akan semakin meningkat. Data yang disodorkan Persatuan Gerontologi Medik Indonesia, menyebutkan pada tahun 2015, jumlah lansia di Indonesia akan mencapai 36 juta orang atau $11,34 \%$ dari populasi penduduk.

Otak manusia seperti hologram, terdiri atas tiga dimensi dengan bagian-bagian yang saling berhubungan sebagai satu kesatuan. Pelajaran lebih mudah diterima apabila mengaktifkan sejumlah panca indera daripada hanya diberikan secara abstrak saja. Akan tetapi, otak manusia juga spesifik tugasnya, untuk aplikasi gerakan Brain Gym dipakai istilah dimensi lateralitas untuk belahan otak kiri dan kanan, dimensi pemfokusan untuk bagian belakang otak (batang otak atau brainstem) dan bagian depan otak (frontal lobes), serta dimensi pemusatan untuk sistem limbis (midbrain) dan otak besar (cerebral cortex) (Dennison, 2009).

Adapun hasil wawancara yang di lakukan pada sepuluh lansia di RW 06 Kelurahan Pamoyanan Kota Bandung tersebut berkaitan dengan pengetahuan lansia tentang senam otak di dapatkan bahwa seluruh lansia tidak mengetahui apa yang dimaksud dengan senam otak. Namun, ketika lansia diberikan contoh gerakan senam otak tiga dari sepuluh orang lansia mengetahui gerakan tersebut dan satu orang di antaranya mengetahui manfaat dari senam otak tersebut. Senam otak penting diketahui oleh lansia, jika lansia tidak me.ngetahui senam otak, maka lansia akan mengalami daya ingat yang kurang baik.

\section{METODE PENELITIAN}

Penelitian ini dirancang menggunakan penelitian deskriptif karena dalam bertujuan untuk melihat gambaran fenomena yang terjadi di dalam suatu populasi tertentu. (Notoatmodjo, 2010). Populasi dalam penelitian ini adalah lansia di wilayah RW 06 Kelurahan Pamoyanan Kota Bandung yang berusia 45-60 sebanyak 345 lansia. Sampel pada penelitian ini adalah 72 .

Sampel pada penelitian ini adalah lansia berusia 45-60 tahun yang berada di RW 06 Kelurahan Pamoyanan Kota Bandung. Metode sampel yang digunakan adalah purposive sampling.

Skala pengetahuan yang digunakan adalah Guttman, yaitu dengan menjawab pertanyaan yang telah disediakan dengan memberikan tanda ceklis $(\sqrt{ })$ pada jawaban yang dianggap paling benar. Analisis data menggunakan analisis univariat. Untuk mengetahui dan mendeskripsikan distribusi frekuensi dengan skor Baik : 76-100\%, Cukup : 56$75 \%$ dan kurang :>56\%. 


\section{HASIL PENELITIAN}

A. Pengetahuan Berdasarkan Karakteristik Responden

1. Usia

Tabel 1.

Distribusi Frekuensi Pengetahuan Berdasarkan Usia Lansia RW 06 Kelurahan Pamoyanan Kota Bandung

\begin{tabular}{lcccccccc}
\hline Pengetahuan & Baik & \% & Cukup & \% & Kurang & \% & Total \\
\hline \multicolumn{1}{c}{ Usia } & & & & & & & $\sum$ & \\
\hline $45-52$ tahun & 30 & 41,7 & 7 & 9,7 & 0 & 0 & 37 & \\
\hline $53-60$ tahun & 26 & 36,1 & 9 & 12,5 & 0 & 0 & $\mathbf{3 5}$ & \\
\hline Total & $\mathbf{5 6}$ & $\mathbf{7 7 , 8}$ & $\mathbf{1 6}$ & $\mathbf{2 2 , 2}$ & 0 & 0 & $\mathbf{7 2}$ & $\mathbf{1 0 0 \%}$ \\
\hline
\end{tabular}

Berdasarkan tabel di atas bahwa hampir setengahnya dari responden sebanyak 30 orang $(41,7 \%)$ lansia RW 06 Kelurahan Pamoyanan Kota Bandung yang berusia 45-52 tahun memiliki pengetahuan yang baik tentang senam otak.

\section{Jenis Kelamin}

Tabel 2.

Distribusi Frekuensi Pengetahuan Berdasarkan Jenis Kelamin Lansia di RW 06 Kelurahan Pamoyanan Kota Bandung

\begin{tabular}{lcccccccc}
\hline $\begin{array}{c}\text { Pengetahuan } \\
\begin{array}{c}\text { Jenis } \\
\text { Kelamin }\end{array}\end{array}$ & Baik & \% & Cukup & \% & Kurang & \% & Total \\
\hline Laki-laki & 13 & 18,1 & 5 & $\mathbf{6 , 9}$ & 0 & 0 & $\mathbf{1 8}$ & $\mathbf{2 5 , 0 \%}$ \\
\hline Perempuan & $\mathbf{4 2}$ & $\mathbf{5 8 , 3}$ & $\mathbf{1 2}$ & $\mathbf{1 6 , 7}$ & $\mathbf{0}$ & $\mathbf{0}$ & $\mathbf{5 3}$ & $\mathbf{7 5 , 0 \%}$ \\
\hline Total & $\mathbf{5 5}$ & $\mathbf{7 6 , 4}$ & $\mathbf{1 7}$ & $\mathbf{2 3 , 6}$ & $\mathbf{0}$ & $\mathbf{0}$ & $\mathbf{7 2}$ & $\mathbf{1 0 0 \%}$ \\
\hline
\end{tabular}

Berdasarkan tabel di atas bahwa sebagian besar dari responden 42 orang $(58,3 \%)$ lansia di RW 06 Kelurahan Pamoyanan Kota Bandung yang berjenis kelamin perempuan memiliki pengetahuan yang baik tentang senam otak.

\section{Pendidikan}

Tabel 3.

Distribusi Frekuensi Pengetahuan Berdasarkan Pendidikan Lansia RW 06 Kelurahan Pamoyanan Kota Bandung

\begin{tabular}{lcccccccc}
\hline Pengetahuan & Baik & \% & Cukup & \% & Kurang & \% & & Total \\
\hline Pendidikan & & & & & & & $\sum$ & \\
\hline SD & 16 & 22,2 & 10 & 13,9 & 0 & 0 & $\mathbf{2 6}$ & $\mathbf{3 6 , 1}$ \\
\hline SMP & $\mathbf{1 5}$ & $\mathbf{2 0 , 8}$ & $\mathbf{1}$ & $\mathbf{1 , 4}$ & 0 & 0 & $\mathbf{1 6}$ & $\mathbf{2 2 , 2}$ \\
\hline SMA & $\mathbf{1 8}$ & $\mathbf{2 5 , 0}$ & $\mathbf{5}$ & $\mathbf{6 , 9}$ & 0 & 0 & $\mathbf{2 3}$ & $\mathbf{3 1 , 9}$ \\
\hline D1 & $\mathbf{1}$ & $\mathbf{1 , 4}$ & $\mathbf{0}$ & $\mathbf{0}$ & 0 & 0 & $\mathbf{1}$ & $\mathbf{1 , 4}$ \\
\hline D3 & $\mathbf{1}$ & $\mathbf{1 , 4}$ & $\mathbf{0}$ & $\mathbf{0}$ & 0 & 0 & $\mathbf{1}$ & $\mathbf{1 , 4}$ \\
\hline S1 & $\mathbf{4}$ & $\mathbf{5 , 6}$ & $\mathbf{1}$ & $\mathbf{1 , 4}$ & 0 & 0 & $\mathbf{5}$ & $\mathbf{6 , 9}$ \\
\hline Total & $\mathbf{5 5}$ & $\mathbf{7 6 , 4}$ & $\mathbf{1 7}$ & $\mathbf{2 3 , 6}$ & 0 & 0 & $\mathbf{7 2}$ & $\mathbf{1 0 0}$ \\
\hline
\end{tabular}

Berdasarkan tabel di atas menunjukkan bahwa sebagian kecil dari responden sebanyak delapan belas orang $(25,0 \%)$ lansia di RW 06 Kelurahan Pamoyanan Kota Bandung yang berpendidikan terakhir SMA memiliki pengetahuan yang baik tentang senam otak. 


\section{Pekerjaan}

Tabel 4.

Distribusi Frekuensi Pengetahuan Berdasarkan Pekerjaan Lansia RW 06 Kelurahan Pamoyanan Kota Bandung

\begin{tabular}{lcccccccc}
\hline Pengetahuan & Baik & \% & Cukup & \% & Kurang & \% & Total \\
\hline \multicolumn{1}{c}{ Pekerjaan } & & & & & & & & $\sum$ \\
\hline PNS & $\mathbf{6}$ & $\mathbf{8 , 3}$ & $\mathbf{0}$ & $\mathbf{0 , 0}$ & 0 & 0,0 & $\mathbf{6}$ & $\mathbf{8 , 3 \%}$ \\
\hline Wiraswasta & $\mathbf{6}$ & $\mathbf{8 , 3}$ & $\mathbf{4}$ & $\mathbf{5 , 6}$ & 0 & 0,0 & $\mathbf{1 0}$ & $\mathbf{1 3 , 9 \%}$ \\
\hline Wirausaha & $\mathbf{8}$ & $\mathbf{1 1 , 1}$ & $\mathbf{2}$ & $\mathbf{2 , 8}$ & 0 & 0,0 & $\mathbf{1 0}$ & $\mathbf{1 3 , 9 \%}$ \\
\hline Buruh & $\mathbf{2}$ & $\mathbf{2 , 8}$ & $\mathbf{0}$ & $\mathbf{0 , 0}$ & 0 & 0,0 & $\mathbf{2}$ & $\mathbf{2 , 8 \%}$ \\
\hline Tidak bekerja & $\mathbf{1}$ & $\mathbf{1 , 4}$ & $\mathbf{2}$ & $\mathbf{2 , 8}$ & 0 & 0,0 & $\mathbf{3}$ & $\mathbf{4 , 2 \%}$ \\
\hline IRT & $\mathbf{3 2}$ & $\mathbf{4 4 , 4}$ & $\mathbf{9}$ & $\mathbf{1 2 , 5}$ & 0 & 0,0 & $\mathbf{4 1}$ & $\mathbf{5 6 , 9 \%}$ \\
\hline Total & $\mathbf{5 5}$ & $\mathbf{7 6 , 4}$ & $\mathbf{1 7}$ & $\mathbf{2 3 , 6}$ & 0 & 0,0 & $\mathbf{7 2}$ & $\mathbf{1 0 0}$ \\
\hline
\end{tabular}

Berdasarkan tabel di atas menunjukkan bahwa hampir setengahnya dari responden sebanyak 32 orang $(44,4 \%)$ lansia di RW 06 Kelurahan Pamoyanan Kota Bandung yang mempunyai pekerjaan sebagai ibu rumah tangga memiliki pengetahuan yang baik tentang senam otak.

\section{B. Pengetahuan Responden Berdasarkan Indikator Pernyataan 1. Pengertian}

Tabel 5.

Distribusi Frekuensi Pengetahuan Lansia Tentang Pengertian Senam Otak RW 06 Kelurahan Pamoyanan Kota Bandung

\begin{tabular}{|l|c|c|}
\hline \multicolumn{1}{|c|}{ Pengetahuan } & Frekuensi & Persentase (\%) \\
\hline Pengertian & & \\
\hline Baik & 52 & 72,2 \\
\hline Cukup & 0 & 0 \\
\hline Kurang & 20 & 27,0 \\
\hline Total & 72 & 100 \\
\hline
\end{tabular}

Berdasarkan tabel di atas menunjukkan bahwa sebagian besar dari responden sebanyak 52 orang (72,2\%) lansia di RW 06 Kelurahan Pamoyanan Kota Bandung memiliki pengetahuan baik tentang pengertian senam otak.

\section{Manfaat Senam Otak}

Tabel 6.

Distribusi Frekuensi Pengetahuan lansia tentang manfaat senam otak RW 06 Kelurahan Pamoyanan Kota Bandung

\begin{tabular}{|l|c|c|}
\hline \multicolumn{1}{|c|}{ Pengetahuan } & Frekuensi & Persentase (\%) \\
\hline Manfaat & & \\
\hline Baik & 65 & 90,3 \\
\hline Cukup & 7 & 9,7 \\
\hline Kurang & 0 & 0 \\
\hline Total & 72 & 100 \\
\hline
\end{tabular}

Berdasarkan tabel di atas menunjukkan bahwa hampir seluruhnya dari responden sebanyak 65 orang $(90,3 \%)$ lansia di RW 06 Kelurahan Pamoyanan Kota Bandung memiliki pengetahuan yang baik tentang manfaat senam otak. 


\section{Indikasi Senam Otak}

Tabel 7.

Distribusi Frekuensi Pengetahuan Lansia Tentang Indikasi Senam Otak RW 06 Kelurahan Pamoyanan Kota Bandung Pengetahuan Frekuensi Persentase

\begin{tabular}{|l|c|c|}
\hline \multicolumn{1}{|c|}{ Pengetahuan } & Frekuensi & Persentase (\%) \\
\hline Indikasi & & \\
\hline Baik & 50 & 69,4 \\
\hline Cukup & 12 & 16,7 \\
\hline Kurang & 10 & 13,9 \\
\hline Total & 72 & 100 \\
\hline
\end{tabular}

Berdasarkan tabel di atas menunjukkan bahwa sebagian besar dari responden sebanyak 50 orang $(69,4 \%)$ lansia di RW 06 Kelurahan Pamoyanan Kota Bandung memiliki pengetahuan yang baik tentang indikasi senam otak.

\section{Kontra Indikasi Senam Otak}

Tabel 8.

Distribusi Frekuensi Pengetahuan Lansia Tentang Kontra Indikasi Senam Otak RW 06 Kelurahan Pamoyanan Kota Bandung

\begin{tabular}{|l|c|c|}
\hline \multicolumn{1}{|c|}{ Pengetahuan } & Frekuensi & Persentase (\%) \\
\hline Kontra Indikasi & & \\
\hline Baik & 9 & 12,5 \\
\hline Cukup & 8 & 11,1 \\
\hline Kurang & 55 & 76,4 \\
\hline Total & 72 & 100 \\
\hline
\end{tabular}

Berdasarkan tabel di atas menunjukkan bahwa hampir seluruhnya dari responden sebanyak 55 orang (76,4\%) lansia di RW 06 Kelurahan Pamoyanan Kota Bandung memiliki pengetahuan yang kurang tentang kontra indikasi senam otak.

\section{Gerakan Senam Otak}

Tabel 9.

Distribusi Frekuensi Pengetahuan Lansia Tentang Gerakan Senam Otak RW 06 Kelurahan Pamoyanan Kota Bandung

\begin{tabular}{|l|c|c|}
\hline \multicolumn{1}{|c|}{ Pengetahuan } & Frekuensi & Persentase (\%) \\
\hline Gerakan & & \\
\hline Baik & 52 & 72,2 \\
\hline Cukup & 19 & 26,4 \\
\hline Kurang & 1 & 1,4 \\
\hline Total & 72 & 100 \\
\hline
\end{tabular}

Berdasarkan tabel di atas menunjukkan bahwa sebagian besar dari responden sebanyak 52 orang (72,2\%) lansia di RW 06 Kelurahan Pamoyanan Kota Bandung memiliki pengetahuan yang baik tentang gerakan senam otak. 


\section{PEMBAHASAN}

\section{A. Pengetahuan Lansia Tentang Senam}

Otak Berdasarkan Karakteristik

\section{Tingkat Pengetahuan Berdasarkan Usia}

Berdasarkan tabel 4.5 pengetahuan lansia RW 06 Kelurahan pamoyanan Kota Bandung tentang senam otak hampir setengahnya dari responden $41,7 \%$ (30 orang) yang berusia 45 52 tahun memiliki pengetahuan yang baik. Menurut Huclok dalam Wawan (2010), Semakin cukup umur, tingkat kematangan dan kekuatan seseorang akan lebih matang dalam berpikir dan bekerja. Semakin tinggi usia akan berpengaruh terhadap pengetahuan lansia. Namun pengetahuan lansia juga bisa rendah disebabkan fungsi kemampuan belajar yang tidak dikembangkan.

\section{Tingkat Pengetahuan Berdasarkan Pendidikan.}

Berdasarkan tabel di atas menunjukkan bahwa sebagian kecil dari responden sebanyak 18 orang $(25,0 \%)$ lansia di RW 06 Kelurahan Pamoyanan Kota Bandung yang berpendidikan terakhir SMA memiliki pengetahuan yang baik tentang senam otak. Pendidikan berarti bimbingan yang diberikan seseorang terhadap perkembangan orang lain menunjukkan ke arah cita-cita tertentu yang menentukan manusia untuk berbuat dan mengisi kehidupan untuk mencapai keselamatan dan kebahagiaan. Pendidikan diperlukan untuk mendapatkan informasi misalnya hal-hal yang menunjang kesehatan sehingga dapat meningkatkan kualitas hidup.

Pada penelitian ini hampir setengahnya dari responden 26 orang $(36,1 \%)$ berpendidikan SD. Hal ini sejalan dengan yang dikemukakan YB Mantra yang dikutip Notoatmodjo dalam Wawan (2010), pendidikan dapat mempengaruhi seseorang termasuk juga perilaku seseorang akan pola hidup terutama dalam memotivasi untuk sikap berperan serta dalam pembangunan (Nursalam dalam Wawan 2010).

\section{Tingkat Pengetahuan Berdasarkan Pekerjaan}

Pada penelitian ini berdasarkan tabel di atas menunjukkan bahwa hampir setengahnya dari responden sebanyak 32 orang $(44,4 \%)$ lansia di RW 06 Kelurahan Pamoyanan Kota Bandung yang mempunyai pekerjaan sebagai ibu rumah tangga memiliki pengetahuan yang baik tentang senam otak. Menurut Musrofi memasak melibatkan otak dan dapat membuat otak lebih kreatif dalam penyajiannya.

\section{Tingkat Pengetahuan Berdasarkan Jenis Kelamin}

Berdasarkan tabel di atas bahwa sebagian besar dari responden 42 orang $(58,3 \%)$ lansia di RW 06 Kelurahan Pamoyanan Kota bandung yang berjenis kelamin perempuan memiliki pengetahuan yang baik tentang senam otak. Hasil penelitian tersebut didukung dengan teori yang menyatakan bahwa pusat memori (hippocampus) pada otak wanita lebih besar ketimbang pada otak pria. Ini terbukti bahwa pada pria lebih sering lupa, sementara wanita bisa mengingat segala dengan detail (Lisnaini, 2012).

\section{B. Tingkat Pengetahuan Berdasarkan Indikator Pernyataan}

\section{Tingkat Pengetahuan Pengertian Senam Otak}

Pada penelitian ini menunjukkan bahwa $72,2 \%$ lansia di RW 06 Kelurahan Pamoyanan Kota Bandung memiliki pengetahuan baik tentang pengertian senam otak. Dari dua pernyataan mengenai pengertian senam otak sebanyak 58 orang (80\%) menjawab benar dan empat belas orang $(19,4 \%)$ menjawab salah.

Senam otak merupakan rangkaian gerakan sederhana yang dapat menyeimbangkan setiap bagian-bagian otak atau latihan berbasis 
gerakan tubuh sederhana yang dapat dilakukan di mana saja dan kapan saja (Setyoadi dan Kushariyadi, 2011).

\section{Tingkat Pengetahuan Manfaat senam otak}

Pada penelitian ini $90,3 \%$ memiliki pengetahuan baik. Dari sepuluh pernyataan mengenai manfaat senam otak diketahui $83,3 \%$ lansia menjawab benar dan $16,6 \%$ menjawab salah pada salah satu gerakan senam otak yang bermanfaat untuk mempelajari hal-hal baru karena gerakan tersebut dapat merangsang bagian otak yang menerima informasi dan bagian yang menggunakan informasi dan senam otak dapat mengaktifkan otak pada tiga dimensi salah satunya adalah pemfokusan dan pemahaman.

\section{Tingkat Pengetahuan Indikasi Senam Otak}

Pada penelitian ini sebanyak $69,4 \%$ lansia di RW 06 Kelurahan Pamoyanan Kota Bandung memiliki pengetahuan yang baik tentang indikasi senam otak. Dari lima pernyataan mengenai indikasi senam otak sebanyak $83,3 \%$ (60 orang) menjawab benar dan $16,6 \%$ (12 orang) menjawab salah pada salah satu pernyataan mengenai indikasi senam otak dapat dilakukan pada lansia yang daya ingatnya sudah menurun.

Seiring bertambahnya usia semakin banyak penurunan yang terjadi pada lansia salah satunya adalah penurunan kognitif. maka dari itu senam otak diindikasikan untuk meningkatkan daya ingat dan meningkatkan konsentrasi jika dilakukan secara teratur.

\section{Tingkat Pengetahuan Kontra Indikasi Senam Otak}

Pada penelitian ini sebanyak 76,4\% lansia di RW 06 Kelurahan Pamoyanan Kota Bandung memiliki pengetahuan yang kurang tentang kontra indikasi senam otak. Dari tiga pernyataan mengenai kontra indikasi senam otak sebanyak 25\% (18 orang) menjawab salah dan $75 \%$ (54) menjawab benar pada salah satu pernyataan bahwa senam otak tidak boleh dilakukan pada pasien stroke. Pernyataan tersebut adalah pernyataan negatif, dalam hal ini. Responden menjawab salah maka jawaban tersebut memiliki nilai 1 . Secara teori pasien stroke mengalami gejala kelumpuhan dan kelemahan pada separuh badannya dan dilakukan terapi. Lain halnya pada senam otak memerlukan latihan dan gerakan tubuh sederhana yang dapat dilakukan kapan saja (Setyoadi dan Kushariyadi 2011).

\section{Tingkat Pengetahuan Gerakan Senam Otak}

Pada penelitian sebanyak 72,2\% lansia di RW 06 Kelurahan Pamoyanan Kota Bandung memiliki pengetahuan yang baik tentang gerakan senam otak. Dari delapan gambar dan pernyataan yang diperlihatkan kepada responden mengenai gerakan senam otak $83,3 \%$ (60 orang) menjawab benar dan $16,6 \%$ (12 orang) menjawab salah pada salah satu gambar dan pernyataan yang diberikan adalah gerakan senam otak.

Sesuai dengan teori yang dikemukakan oleh Dennison (2006) bahwa senam otak (brain gym) adalah serangkaian gerak sederhana yang menyenangkan dan dapat digunakan berbagai usia dan gerakan-gerakan pada brain gym dapat memberikan rangsangan atau stimulus ialah yang dapat meningkatkan kognitif.

\section{SIMPULAN DAN SARAN}

Berdasarkan hasil penelitian dan pembahasan, maka dapat ditarik kesimpulan sebagai berikut.

1. Sebanyak 52 orang $(72,2 \%)$ lansia di RW 06 Kelurahan Pamoyanan Kota Bandung memiliki pengetahuan baik tentang pengertian senam otak.

2. Sebanyak 65 orang $(90,3 \%)$ lansia di RW 06 Kelurahan Pamoyanan Kota Bandung 
memiliki pengetahuan baik tentang manfaat senam otak.

3. Sebanyak 50 orang $(69,4 \%)$ lansia di RW 06 Kelurahan Pamoyanan Kota Bandung memiliki pengetahuan yang baik tentang indikasi senam otak.

4. Sebanyak 55 orang $(76,4 \%)$ lansia di RW 06 Kelurahan Pamoyanan Kota Bandung memiliki pengetahuan kurang tentang Kontra Indikasi Senam Otak.

5. Sebanyak 52 orang $(72,2 \%)$ lansia di RW 06 Kelurahan Pamoyanan Kota Bandung memiliki pengetahuan yang baik tentang gerakan senam otak.

Pada penelitian ini hamper seluruhnya dari responden $76,4 \%$ (55 orang) memiliki pengetahuan baik mengenai senam otak.

\section{SARAN}

1. Bagi Instansi Puskesmas

Diharapkan kepada petugas kesehatan di Puskesmas Pasirkaliki agar melakukan kegiatan senam otak pada lansia di RW 06 Kelurahan Pamoyanan Kota Bandung.

2. Bagi Instritusi Pendidikan

Diharapkan kepada institusi pendidikan agar hasil penelitian ini dapat dijadikan referensi untuk meningkatkan pengembangan ilmu pengetahhuan mengenai senam otak.

3. Bagi Peneliti Selanjutnya

Diharapkan untuk peneliti selanjutya agar membuat kuesioner yang lebih mudah dipahami oleh responden.

\section{REFERENSI}

A.Wawan dan Dewi M. 2010. Teori dan Pengukuran Pengetahuan, Sikap, dan Perilaku Manusia. Yogyakarta: Nuha Medika.

Dennison, Paul E dan Dennison Gail E.2009. Brain Gym. Jakarta: PT Gramedia.

Lisnaini. 2010. Senam Vitalisasi Otak Dapat Meningkatkan Fungsi Kognitif Usia Dewasa Muda.

Notoatmodjo, Soekidjo. 2010. Metodoogi Penelitian Kesehatan. Jakarta : PT Rineka Cipta.

Profil Dinas Kesehatan. 2014.

Sugiyono. 2012. Metode Penelitian Kuantitatif dan Kualitatif dan $R \& D$. Bandung: Alfabeta. 